\title{
AERODYNAMICS OF HIGH-SIDED \\ VEHICLES ON TRUSS GIRDER CONSIDERING SHELTERING EFFECT BY WIND TUNNEL TESTS
}

\author{
JINGYU ZHANG ${ }^{1}$, MINGJIN ZHANG ${ }^{*}$, YONGLE LI ${ }^{3}$, \\ XU HUANG ${ }^{4}, Z^{2}$ HONG ZHENG ${ }^{5}$ \\ ${ }^{1-4}$ Department of Bridge Engineering, Southwest Jiaotong University, \\ Chengdu 610031, China \\ ${ }^{5}$ Sichuan Yakang Expressway Co., Ltd., Chengdu 610041, China
}

Received 8 May 2019; accepted 14 October 2019

\begin{abstract}
Aerodynamic characteristics of vehicles are directly related to their running safety, especially for the high-sided vehicles. In order to study the aerodynamic characteristics under multiple sheltering conditions, a complex large scale (1:20.4) truss model and three high-sided vehicles including articulated lorry, travelling bus and commercial van models with the same scale were built. The aerodynamic coefficients under various sheltering effects of wind barriers with different heights and porosities, bridge tower and the vehicle on the adjacent lane were measured. According to the results, wind barriers can effectively reduce wind speed behind them, thus decreasing the wind load acting on the vehicle, which causes the decrease of the aerodynamic response
\end{abstract}

* Corresponding author. E-mail: Zhang-Minjin@swjtu.edu.cn

Jingyu ZHANG (ORCID iD 0000-0002-5597-7738)

Mingjin ZHANG (ORCID iD 0000-0001-5681-5901)

Yongle LI (ORCID iD 0000-0001-9879-0626)

Xu HUANG (ORCID iD 0000-0002-7127-8953)

Zhong ZHENG (ORCID iD 0000-0001-5627-1190)

Copyright (C) 2020 The Author(s). Published by RTU Press

This is an Open Access article distributed under the terms of the Creative Commons Attribution License (http://creativecommons.org/licenses/by/4.0/), which permits unrestricted use,

distribution, and reproduction in any medium, provided the original author and source are credited. 
of all three vehicles. However, the influence at the leeward side is limited due to installation of central stabilizers. When the vehicle passes through the bridge tower, a sudden change occurs, the aerodynamic coefficients decrease and fluctuate in varying degrees, especially for the commercial van. When the vehicle moves in different lanes behind the bridge tower, the sheltering effect of the tower on the aerodynamic coefficient in Lane 1 is much greater than that in Lane 2. With regard to the interference between two vehicles on the adjacent lanes, the relative windward area between the test vehicle and the interference vehicle greatly affects the aerodynamics of the test vehicle.

Keywords: aerodynamic coefficient, bridge tower, complex truss, road vehicle, wind tunnel tests, wind barriers.

\section{Introduction}

Long-span bridges demonstrate superior behaviors; construction of long-span bridges can shorten the running time of vehicles and create great economic value. Thus, many long-span bridges are built over canyons, lakes, rivers and other natural obstacles. For example, after construction of the Aizhai Bridge located in Hunan Province in Central China, the travel time has shortened by nearly three hours. Due to more complex wind environment in such places, especially in the mountainous areas (J. Zhang, Zhang, Li, \& Fang, 2019b; M. Zhang, Yu, Zhang, Wu, \& Li, 2019), the effect of crosswind on vehicles is more obvious. In addition, complex and changeable environment will make the loads acting on bridges more complex (Ti, Zhang, Li, \& Wei, 2019; J. Zhang, Wei, \& Qin, 2019), thus, high-sided lorries, trucks and travelling buses are under risk of rollover when running through long span bridges (Chen \& Cai,

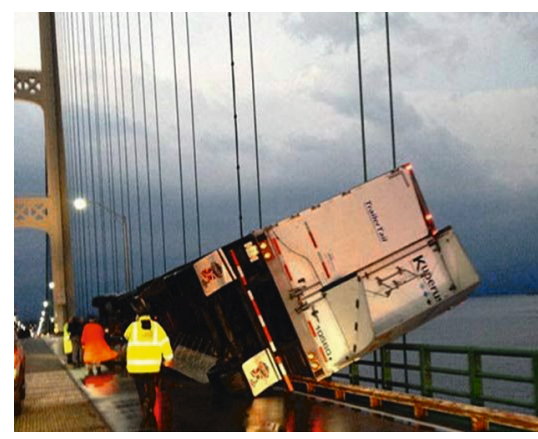

a)

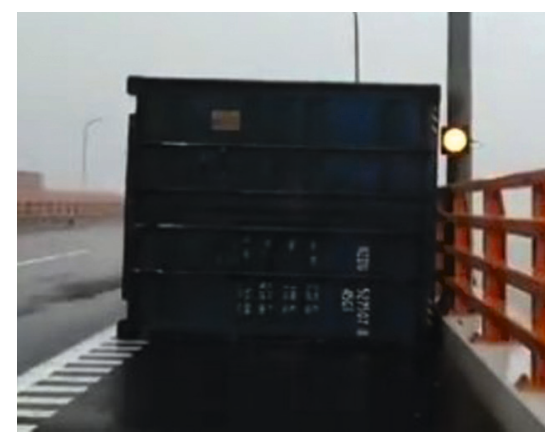

b)

Aerodynamics of High-Sided

Vehicles on Truss Girder Considering Sheltering Effect by Wind Tunnel Tests

Figure 1. Vehicle accidents on long span bridges: a) Mackinac Bridge, b) Hangzhou Bay Bridge 
2004; Coleman \& Baker, 1990, 1992; Xiang, Li, Chen, \& Liao, 2014). Windinduced vehicle accidents occur frequently (Baker \& Reynolds, 1992), e.g. a high-sided lorry was overturned by wind when the vehicle was running on the Mackinac Bridge in July, 2013, similar accident occurred on the Hangzhou Bay Bridge in August, 2018.

Aerodynamic characteristics of vehicles were first studied considering the railway transport. The aerodynamic characteristics of trains on different railway constructions, such as embankments and viaducts, were investigated by numerical methods and wind tunnel tests (Avila-Sanchez, Pindado, Lopez-Garcia, \& Sanz-Andres, 2014; He, Zou, Wang, Han, \& Shi, 2014; Schober, Weise, Orellano, Deeg, \& Wetzel, 2010; Suzuki, Tanemoto, \& Maeda, 2003). This research demonstrated that the line form has a great impact on the aerodynamic characteristics. Besides, some researchers studied the effect of line connection zone, such as embankment-cutting connection zone, on the aerodynamic performance; the effect of change of line form on the aerodynamics was studied as well (Bocciolone, Cheli, Corradi, Muggiasca, \& Tomasini, 2008; Li, Zhang, Zhang, Wang, \& Guo, 2019; Liu \& Zhang, 2013; J. Zhang, Zhang, Li, \& Fang, 2019a).

As far as road vehicles are concerned, the studies of aerodynamic characteristics of road vehicles under several situations were carried out. The influence of vehicle shape on vehicle aerodynamic performance was studied using wind tunnel tests (Hucho \& Sovran, 1993). Sensitivity of aerodynamic forces acting on the heavy road vehicle under various situations was analyzed by wind tunnel tests. It was established that the aerodynamic force acting on the vehicle was affected by the yaw angle. The influence of infrastructure scenario, such as flat ground and viaduct, was studied as well (Cheli, Corradi, Sabbioni, \& Tomasini, 2011; Cheli, Ripamonti, Sabbioni, \& Tomasini, 2011). Taking a box girder as an object, Han et al. $(2013,2019)$ developed a wind tunnel test model to investigate the aerodynamic coefficients under different situations including different incoming flow speed, locations of vehicles on the bridge deck, wind directions, and different wind field types. Wind barriers widely used as the most common means of wind protection were also studied (Kennedy, 1997; Kozmar, Procino, Borsani, \& Bartoli, 2012; Wang \& Takle, 1996). According to test results, wind barriers can effectively decrease the aerodynamic forces acting on a vehicle to decrease wind speed (Charuvisit, Kimura, \& Fujino, 2004). In addition, the protection effect of porous wind break with different heights and porosities on road vehicles against crosswind was investigated using wind tunnel tests and Large Eddy Simulation models (Chu et al., 2013). In the case of the long-span bridge, the effect of bridge tower cannot be ignored, therefore, some researchers studied the effect of bridge 

\& Zasso, 2011; Li, Hu, Cai, Zhang, \& Qiang, 2013; Wu, Li, \& Zhang, 2017; $\mathrm{Xu} \&$ Guo, 2004). Charuvisit, Kimura and Fujino (2004) investigated the influence of the shape of the bridge tower; the results showed that the aerodynamic characteristics of vehicles changed considerably when the vehicles were behind the tower, the shelter effect of the tower creating a sudden change. Taking a single-tower box-girder bridge as an object, the aerodynamic loads and the surface pressure distribution were investigated by wind tunnel tests. It was concluded that the presence of the tower produces a sudden change in the sign of the lateral force and the overturning moment (Argentini et al., 2011). Investigation of aerodynamic coefficients of road vehicles can help researches in the analysis of coupling dynamic of wind-vehicle-bridge (Zhu \& Zhang, 2018; Zhu, Zhang, \& Li, 2019).

Taking a complex truss structure as a research object in this paper, the aerodynamic characteristics of different vehicles including articulated lorry, travelling bus and commercial van were measured. In order to consider the shelter effects of various situations, different wind barriers with various heights and porosities and bridge tower were introduced and the aerodynamic coefficients were measured. Besides, the interferences between vehicles in adjacent lanes at windward side were tested as well.

\section{Wind tunnel experiment setup}

In order to investigate the aerodynamic coefficients of road vehicles, large-scale wind tunnel tests were carried out in the XNJD-3 wind tunnel at Southwest Jiaotong University. It is a closed-circuit down blowing type facility comprising a boundary test section of $22.5 \mathrm{~m}$ (width) $\times 4.5 \mathrm{~m}$ (height) $\times 36.0 \mathrm{~m}$ (length). The range of wind speed was $0.5-16.5 \mathrm{~m} / \mathrm{s}$. The turbulence intensity of the incoming flow was less than $1.5 \%$ and the thickness of the boundary in the tunnel was less than $0.2 \mathrm{~m}$.

\subsection{Models of bridge, vehicles and wind barriers}

A long-span suspension bridge was studied as a research object in the tests; the elevation view is shown in Figure 2. The bridge named Dadu River Xinkang Bridge is the first long-span suspension bridge and the key project on the Sichuan-Tibetan Expressway. The construction of the bridge has been of great significance for the development of economy and transportation in the Tibetan area. The bridge is located in a deepcut canyon, the wind environment is complex. The ten minutes average 
wind speed is shown in Figure 3. According to the results, the wind speed shows periodic variation with regularity under normal weather and the maximum wind speed is close to $30 \mathrm{~m} / \mathrm{s}$ under the abnormal weather. The model sketch with the scale of 1:20.4 is shown in Figure 4. The adopted bridge model is a complex truss structure with lanes on its upper layer, the deck carries a dual two-lane carriageway, the four lanes are identified as Lanes 1-4 (from the windward side to the leeward side). In addition, central stabilizers, which can improve wind resistance performance of this bridge, are installed in the central line of the bridge. The truss section is $27 \mathrm{~m}$ wide and $8.2 \mathrm{~m}$ high in full scale. For the scaled model, the width is $1323.5 \mathrm{~mm}$, the width of the deck with lanes is $1196.1 \mathrm{~mm}$, and the height is $406.9 \mathrm{~mm}$. To reflect the real environment of the bridge deck, the affiliated facilities, such as railings, the central stabilizer and maintenance walkway, were considered and made. Before the tests, a survey of three models on different roads was carried out; the results are shown in Table 1. In the survey, we considered three most common roads in China. The roads were ranked from high to low: Chengdu-Ya'an Expressway of China (CYE), No.318 China National Highway (CNH 318) and No. 210 and No. 211 Provincial Highway of Sichuan (PHS 210 and PHS 211). According to survey results, the proportion of high-sided vehicles reaches nearly $40 \%$ on the CYE. For the $\mathrm{CNH}$, the percentage of high-sided vehicles remains $30 \%$. The expressway is being built to replace $\mathrm{CNH} 318$, so the proportion of high-sided vehicle will increase after completion of the expressway. High-side vehicles are more vulnerable to cross wind due to their large side area (Cheli, Corradi, Sabbionoi, \& Tomasini, 2011; Cheli, Ripamonti, Sabbionoi, \& Tomasini, 2011), thus, three types of high-side vehicle models used in China were introduced in this study: a commercial van, a travelling bus and an articulated lorry. The dimensions of three vehicles can be obtained from Figure 5. Vehicle models for test were made from ABS plastic plate, the plastic plate can make the model light enough to improve accuracy and provide sufficient stiffness. Due to limited effect of opening type (Perera, 1981), the parameters of the wind barrier

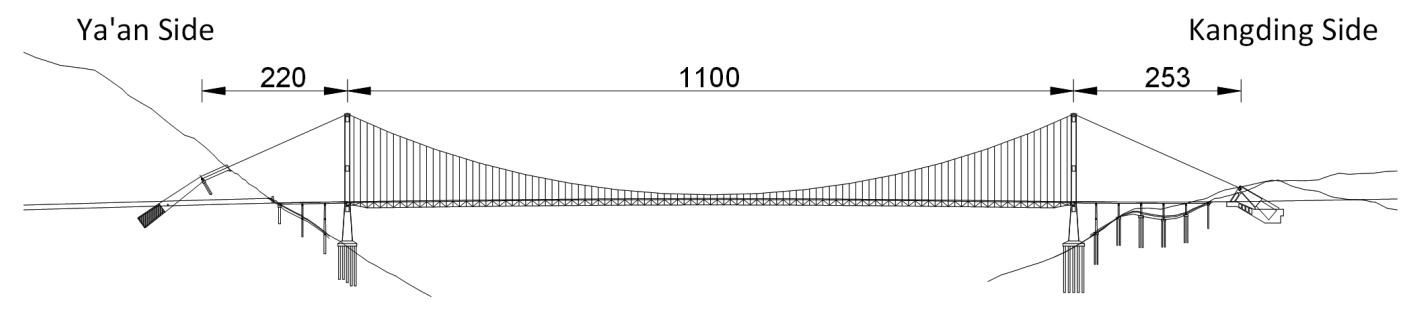

Figure 2. Elevation view of the bridge (unit: $m$ ) 
a)

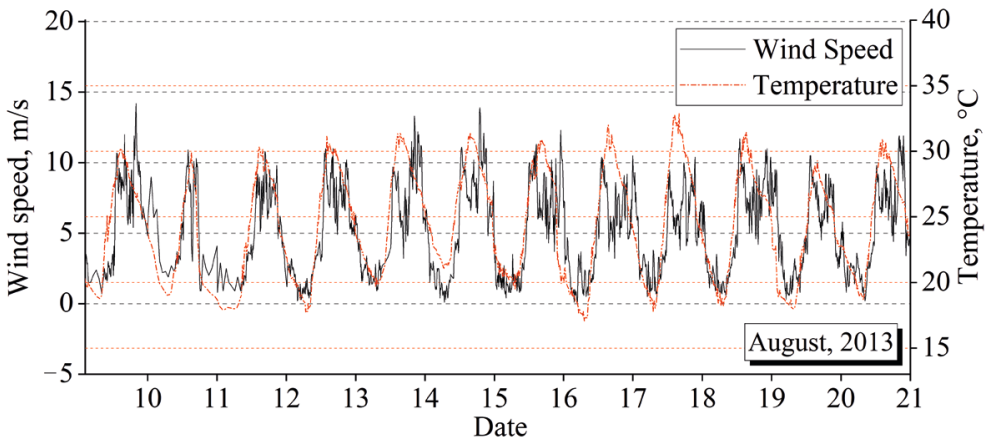

b)

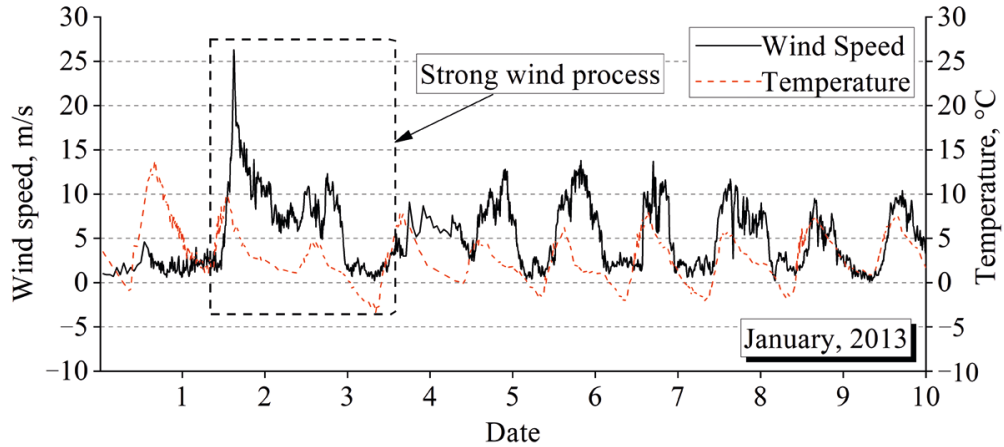

Figure 3. 10-minute average wind speed and temperature: a) normal weather; b) abnormal weather accompanied by strong wind process

including height and porosity were considered. Thus, three different horizontal slotted types of wind barriers made of stiff plastic plate with $2 \mathrm{~mm}$ thickness were investigated in the wind tunnel tests, see Figure 6. The wind barriers were installed on the top of the railings. The first

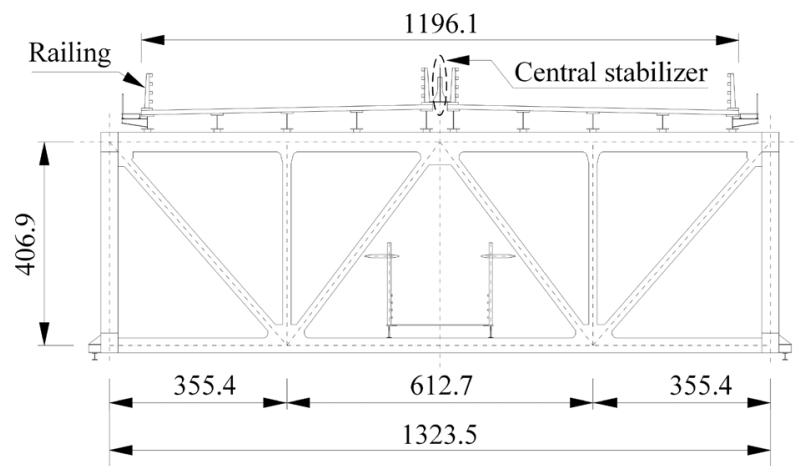

Figure 4. Scaled model of the truss section (unit: $\mathrm{mm}$ )
Jingyu Zhang,

Mingjin Zhang,

Yongle Li,

Xu Huang,

\section{Zhong Zheng}

Aerodynamics of High-Sided

Vehicles on Truss

Girder Considering

Sheltering Effect

by Wind Tunnel Tests 
a)

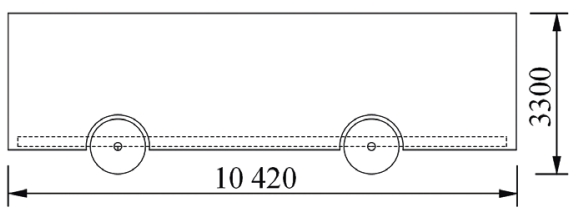

b)

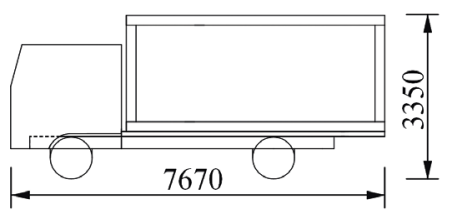

c)

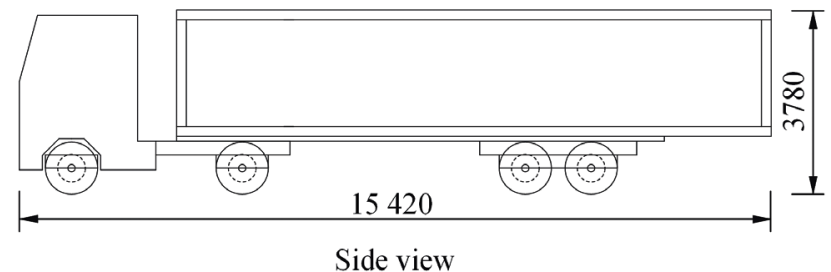

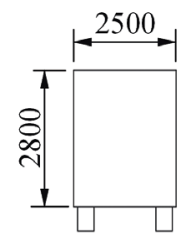
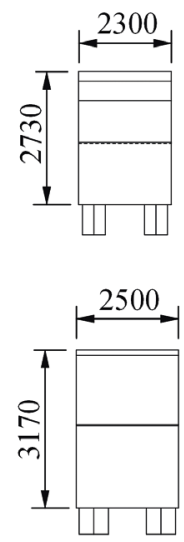

Front view

Figure 5. Geometrical sizes of different vehicles in full scale: a) travelling bus, b) commercial van, c) articulated lorry (unit: $\mathrm{mm}$ )

kind of wind barrier had a height of $2 \mathrm{~m}$ in full scale and porosity of $40 \%$ (WB-1), the second kind of wind barrier had a height of $2 \mathrm{~m}$ in full scale and porosity of 50\% (WB-2), the third kind had a height of $1.2 \mathrm{~m}$ and porosity of $40 \%$ (WB-3). The wind barriers were solidly fixed on the safety fences with rods, the fences and barriers were combined into one whole to protect the vehicle from wind.
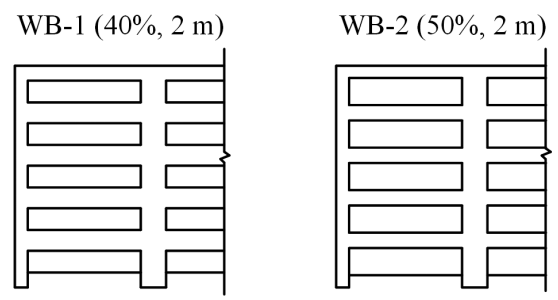

WB-3 (40\%, $1.2 \mathrm{~m})$

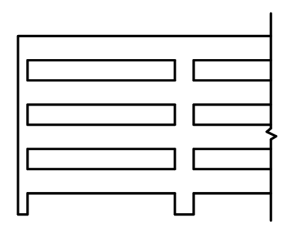

Figure 6. Sketches of wind barriers 
Table 1. Statistics on three high-sided vehicles

in the Sichuan-Tibetan Area

\begin{tabular}{llrrrr}
\hline \multicolumn{1}{c}{$\begin{array}{c}\text { Statistical } \\
\text { location }\end{array}$} & \multicolumn{1}{c}{$\begin{array}{c}\text { Statistical } \\
\text { category }\end{array}$} & $\begin{array}{c}\text { Travelling } \\
\text { bus }\end{array}$ & $\begin{array}{c}\text { Commercial } \\
\text { van }\end{array}$ & $\begin{array}{c}\text { Articulated } \\
\text { lorry }\end{array}$ & Others \\
\hline Ya'an toll station & Count & 253 & 523 & 124 & 2253 \\
(CYE) & Percentage (\%) & 8 & 16.6 & 3.9 & 71.5 \\
\hline Zian toll station & Count & 353 & 483 & 87 & 1532 \\
(CYE) & Percentage (\%) & 14.4 & 19.7 & 3.5 & 62.4 \\
\hline Meiling country & Count & 274 & 187 & 134 & 1363 \\
(CNH 318) & Percentage (\%) & 14 & 9.6 & 6.8 & 69.6 \\
\hline Zishi country & Count & 253 & 152 & 121 & 1242 \\
(CNH 318) & Percentage (\%) & 14.3 & 8.6 & 6.8 & 70.2 \\
\hline Lianglu country & Count & 163 & 138 & 98 & 952 \\
(CNH 318) & Percentage (\%) & 12.1 & 10.2 & 7.3 & 70.5 \\
\hline Nengzi town & Count & 45 & 83 & 13 & 642 \\
(PHS 211) & Percentage (\%) & 5.7 & 10.6 & 1.7 & 82 \\
\hline
\end{tabular}

\subsection{Case description}

In order to study shelter effects of the bridge tower and the interaction of different vehicles on the adjacent lanes on vehicle aerodynamics, the aerodynamic coefficients of different vehicles were tested under various conditions. Prior to that, vehicle aerodynamic coefficients were tested and compared on truss model and twin box girder model. The solid circle in red represents the measuring point (middle of the model), as shown in Figure 7. In order to identify shelter effects of the bridge tower, the influence of the bridge tower on vehicle aerodynamics in the truss model situation was carried out; the size of the tower was $520 \mathrm{~mm}$ (D) $\times 380 \mathrm{~mm}$ (W). The arrangement of measuring points of vehicle aerodynamic coefficients is also shown in Figure 7. Parameter $D$ is the width of the bridge tower, which equals to $520 \mathrm{~mm}$. There are a total of 15 measuring points, shown with 14 hollow circles and one solid circle in red, in each lane; the distance between the adjacent points is $0.25 D(130 \mathrm{~mm})$. Figure 8 is used to describe the spatial position relationship between the test vehicle and the interfering vehicle in order to analyze the effect of interaction of different vehicles in the adjacent lanes on vehicle aerodynamics. Since the test vehicle and interference vehicle may not be the same 


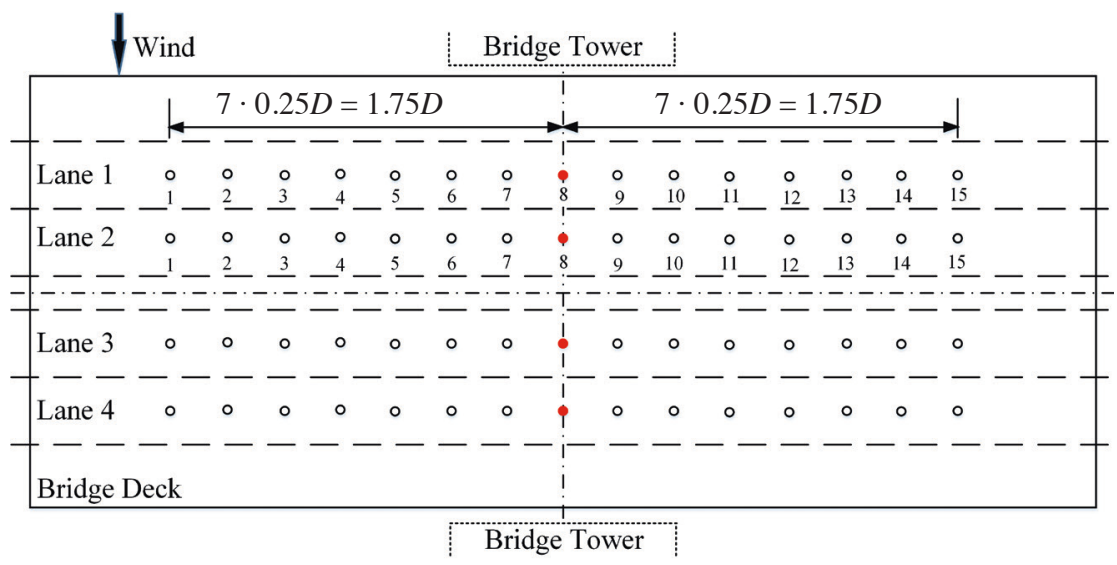

Figure 7. The arrangement of the measuring points of the test vehicle

type of vehicle, in order to describe this relative relationship, we used $l$ and $L$ to represent the length of the test vehicle and interference vehicle, respectively. In the tests, the interaction at windward side was considered. Lane $i$ indicates the lane number of the test vehicle, and Lane $j$ indicates the lane number of the interference vehicle. Five different relative positions were considered in the tests: $\mathrm{P}_{1}$ ) the distance between the back of the test vehicle and the front of the interference vehicle is $l ; \mathrm{P}_{2}$ ) the back of the test vehicle is in the same longitudinal position as the front of the interference vehicle; $\mathrm{P}_{3}$ ) the test vehicle is in the same longitudinal position as the interference vehicle; $\mathrm{P}_{4}$ ) the front of the test vehicle is in the same longitudinal position as the back of the interference vehicle; $P_{5}$ ) the distance between the front of the test vehicle and the back of the interference vehicle is $l$.

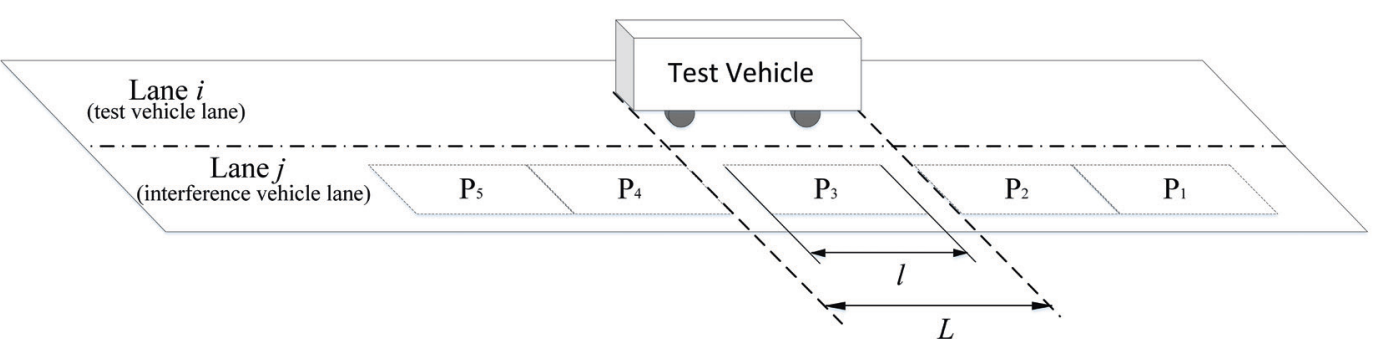

Figure 8. Relative positions between the test vehicle and interference vehicle in the adjacent lanes 


\subsection{Test method and data processing}

In the tests, the free-stream wind speed $V$ was set at $8 \mathrm{~m} / \mathrm{s}$. The vehicle models were hanged on a five-component force balance by using a Z-shaped bracket, and the other end of the bracket was fixed on the center line of the lane on the bridge deck. The sampling time and sampling frequency were set to $50 \mathrm{~s}$ and $400 \mathrm{~Hz}$, respectively. The final data were obtained by averaging all the data collected from the balance. Aerodynamic coefficients, including side $\left(C_{y}\right)$, lift $\left(C_{z}\right)$ force coefficients, rolling $\left(C_{M X}\right)$, yaw $\left(C_{M z}\right)$ and pitching $\left(C_{M y}\right)$ moment coefficients and the related formula are as follows. The definitions of the coordinate system and the direction of aerodynamic forces are shown in Figure 9.

$$
\begin{gathered}
C_{y}=\frac{2 F_{y}}{\rho V_{w}^{2} A_{s}} ; \\
C_{z}=\frac{2 F_{z}}{\rho V_{w}^{2} A_{s}} ; \\
C_{M x}=\frac{2 M_{x}}{\rho V_{w}^{2} A_{s} h_{v}} ; \\
C_{M y}=\frac{2 M_{y}}{\rho V_{w}^{2} A_{s} h_{v}} ; \\
C_{M z}=\frac{2 M_{z}}{\rho V_{w}^{2} A_{s} h_{v}},
\end{gathered}
$$

where $C_{y}, C_{z}, C_{M x}, C_{M y}$, and $C_{M z}$ are side force, lift force, rolling moment, yaw moment and pitching moment, respectively. $F_{y}, F_{z}$ are the mean values of the aerodynamic force component of the side force and lift

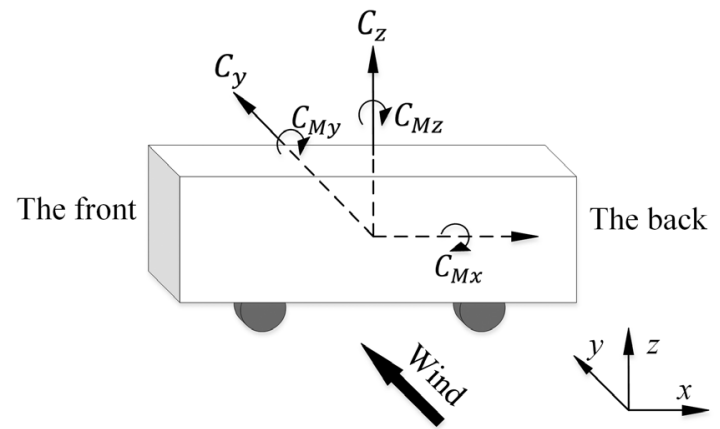

Figure 9. Definition of aerodynamic forces 
force. $M_{x}, M_{y}$ and $M_{z}$ are the mean values of the moment about the rolling moment, yaw moment and pitching moment. $A_{s}$ represents the side area of the vehicle, $h_{v}$ is the height of the vehicle gravity center from the bridge deck, $\rho$ is the air density.

\section{Wind tunnel experiment setup}

\subsection{Aerodynamic coefficients on models}

In order to study vehicle aerodynamic coefficients without the sheltering effects, and considering that the wind environment of the bridge deck will change along the transverse direction of the main girder, four lanes were tested. Figures 10-12 show the aerodynamic coefficients of the commercial van, travelling bus and articulated lorry in different lanes on the bridge deck, respectively. Also, the effect of different wind barriers was considered.

From Figures 10a-12a it can be seen that the installation of a wind barrier on the bridge deck can effectively reduce the side force $\left(C_{y}\right)$ of the vehicles and achieve the minimum value in Lane 4 . Generally speaking, WB-1 has a more significant reduction effect on $C_{y}$ of vehicles. From Figures $10 \mathrm{~b}-12 \mathrm{~b}$ it can be seen that the lift force $\left(C_{z}\right)$ of the vehicle reaches its maximum value in Lane 3. On the windward side, the wind barrier cannot effectively reduce $C_{z}$ of the vehicle, $C_{z}$ even increases in some cases. On the leeward side, especially in Lane $3, C_{z}$ of the vehicle can be significantly reduced. With regard to the influence of rolling moments $\left(C_{M x}\right)$ of vehicles, it can be seen from Figures 10c-12c that the effect of WB-1 is more obvious than that of other wind barriers. As it can be seen from Figures $10 \mathrm{~d}-12 \mathrm{~d}$, for different types of vehicles, the pitch moment $\left(C_{M y}\right)$ of the vehicle is smaller in Lane 2 and Lane 3, mainly because of the central stabilization plate on the main girder. The setting of a wind barrier can reduce $C_{M y}$ of the lanes on both sides and increase $C_{M y}$ of the two lanes in the middle, which can make $C_{M y}$ of each lane in general. It tends to be stable. In Figures $10 \mathrm{e}-12 \mathrm{e}$, the influence of the wind barrier on yaw moment $\left(C_{M Z}\right)$ is not obvious. Only WB-1 stabilizes $C_{M z}$ along the transverse direction of the girder, and the other wind barriers increase the fluctuation of the value. Therefore, the structure of the bridge deck has a significant impact on the aerodynamic coefficients of the vehicles. When the bridge is equipped with wind barriers, the aerodynamic coefficients of vehicles can be more stable in each lane. 


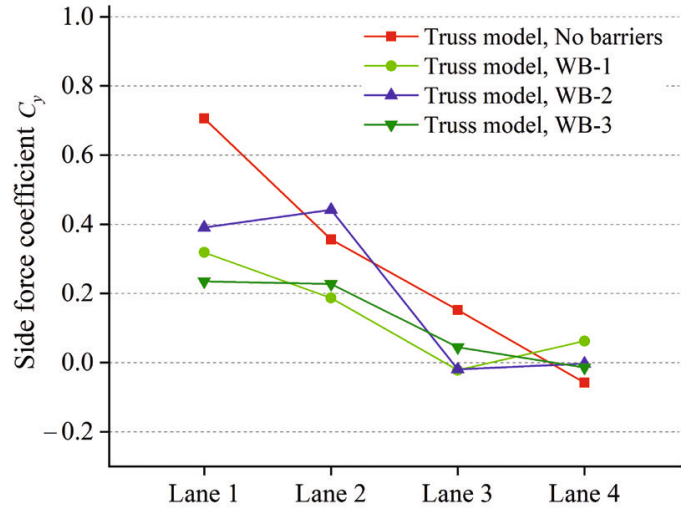

a)

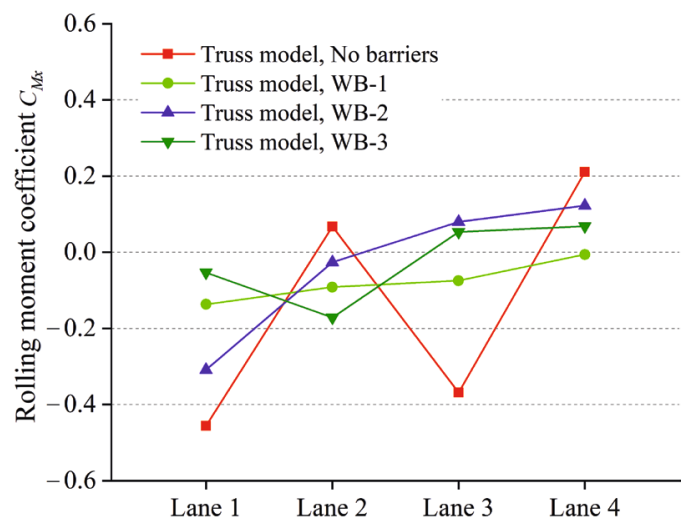

c)

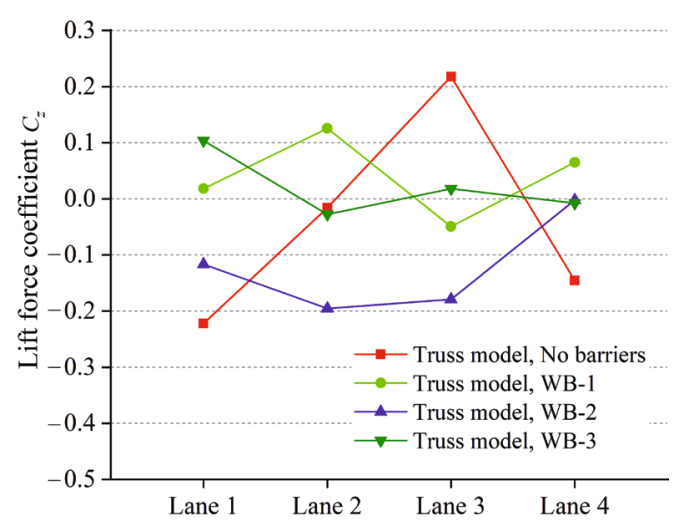

b)

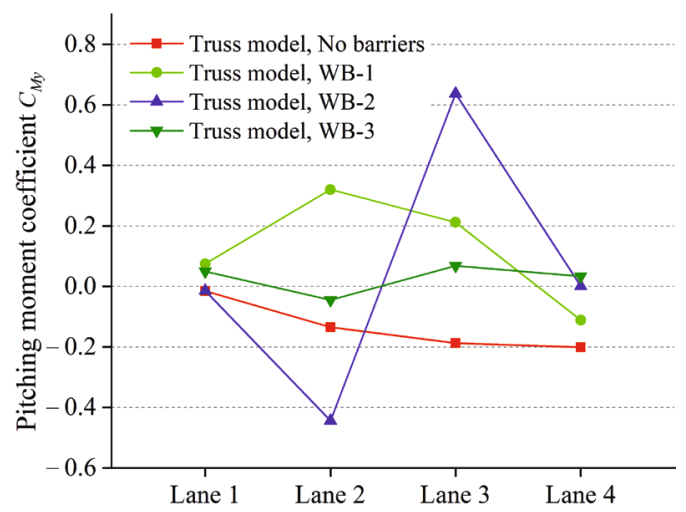

d)

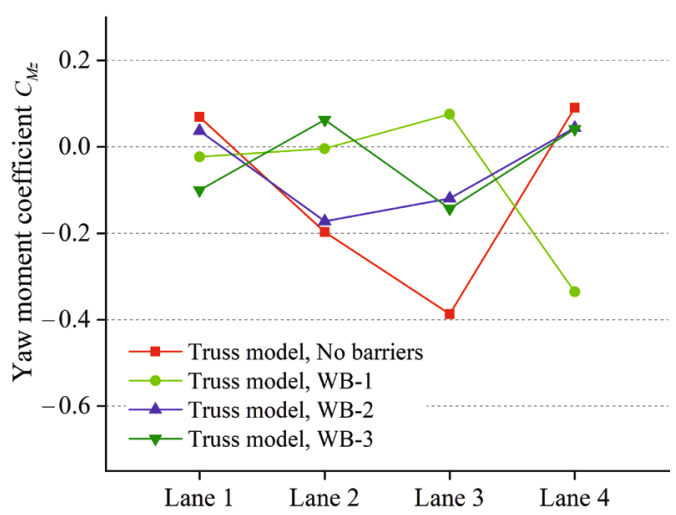

e)

Figure 10. Aerodynamic coefficients of the commercial van 
2020/15(2)

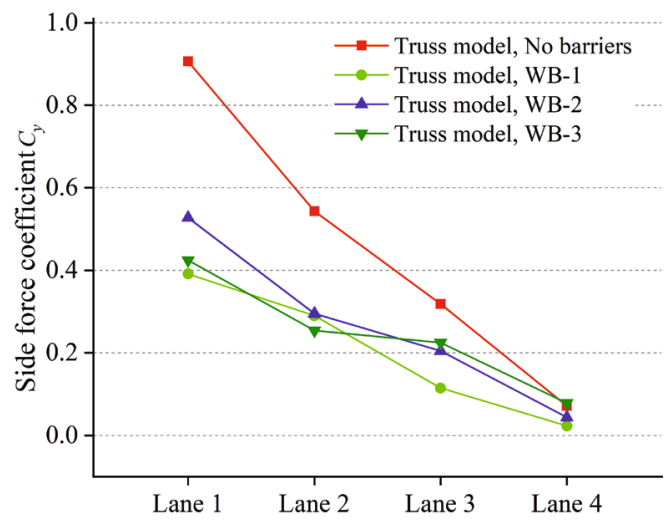

a)

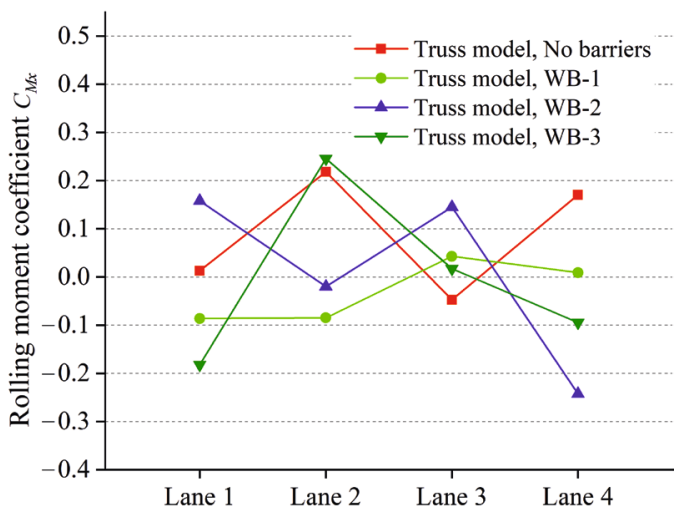

c)

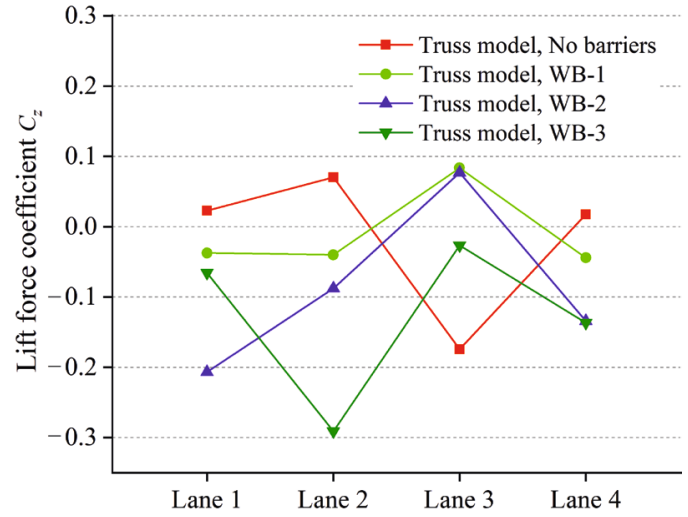

b)

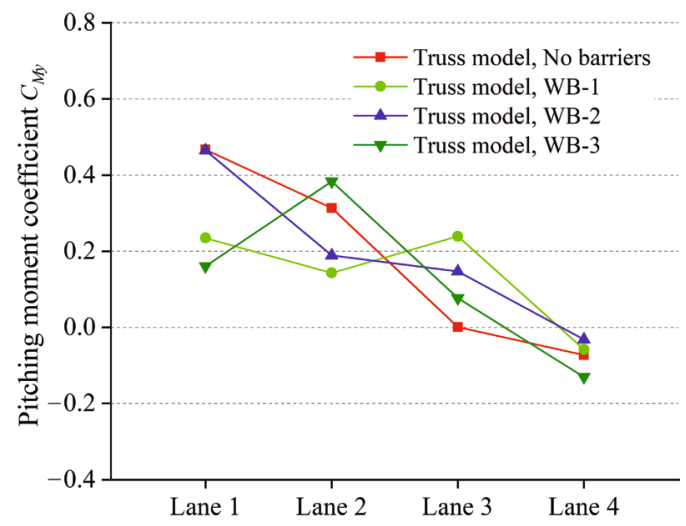

d)

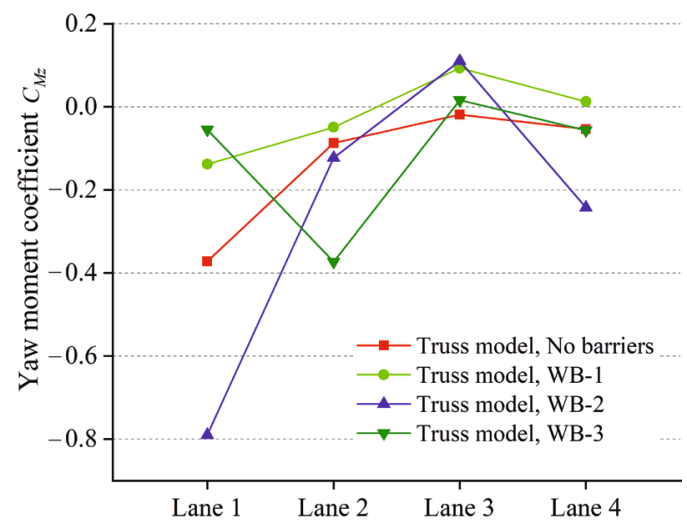

e)

Figure 11. Aerodynamic coefficients of the travelling bus 


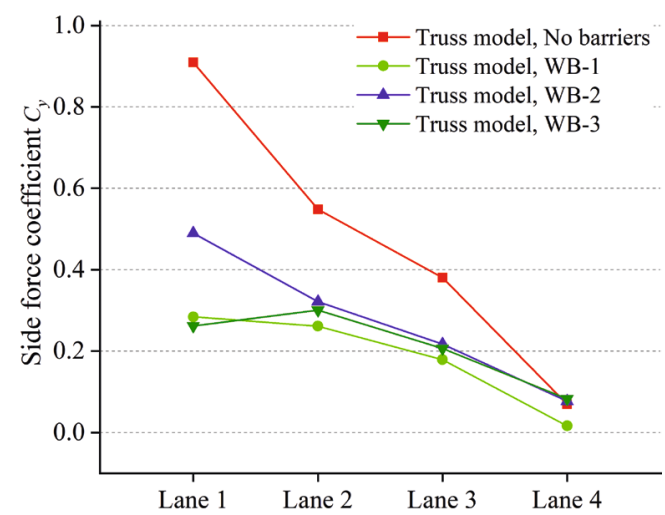

a)

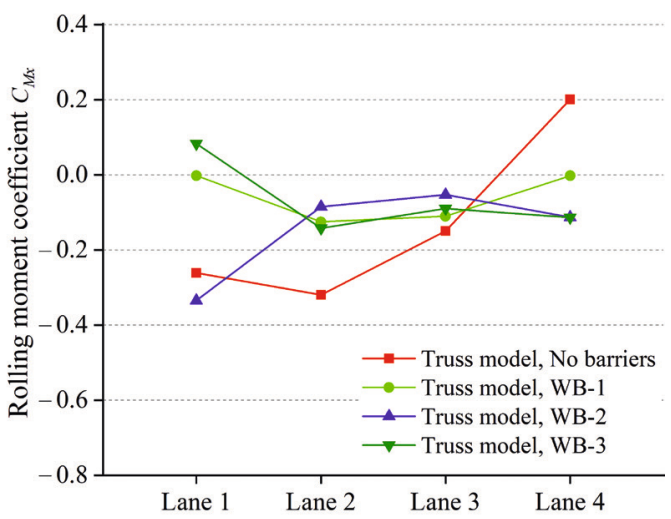

c)

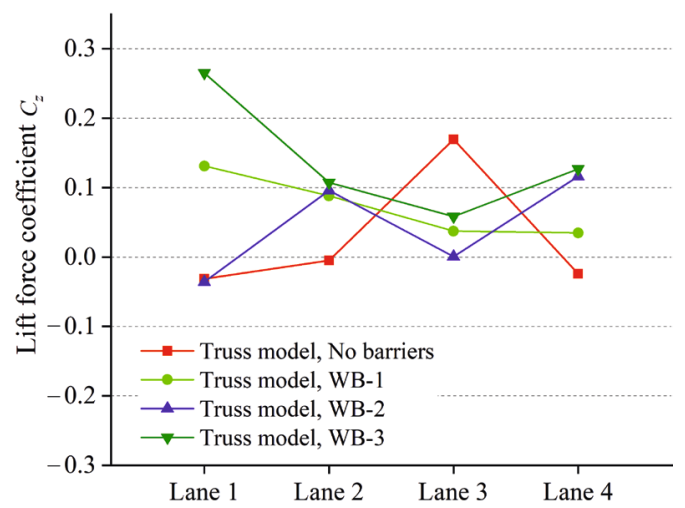

b)

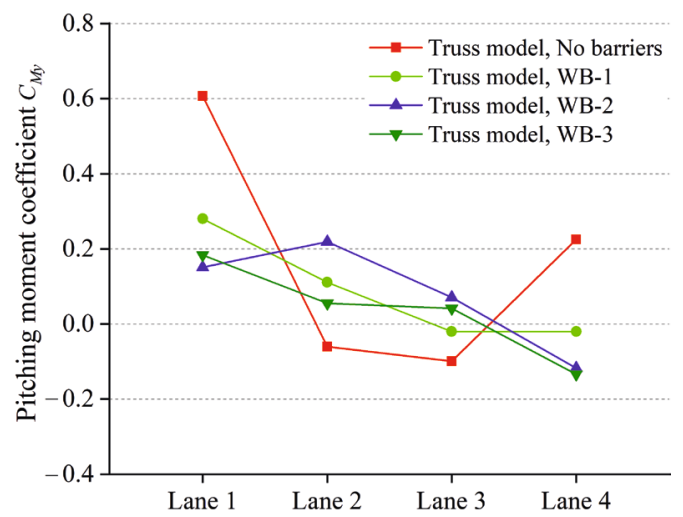

d)

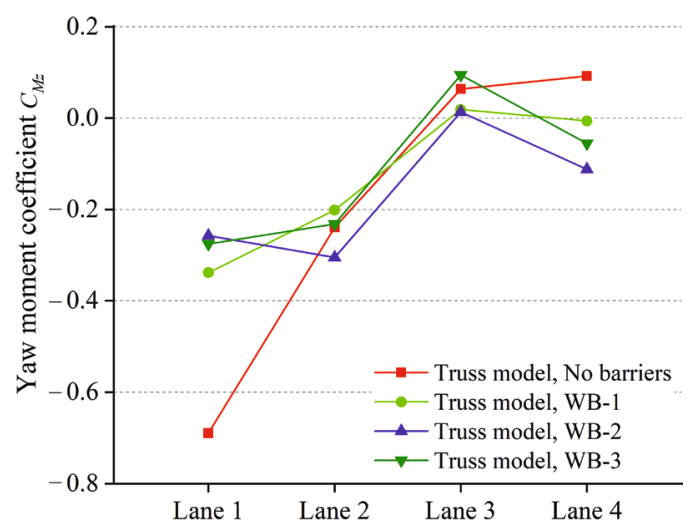

e)

Figure 12. Aerodynamic coefficients of the articulated lorry 


\subsection{The shelter effect of bridge tower}

In the actual driving process, the vehicle will pass through the shelter area of the bridge tower. When entering and leaving the bridge tower, the wind field around the vehicle body will change, which will lead to the sudden change of the aerodynamic coefficient of the vehicle, posing safety-related challenges in the driving process. Therefore, this section is dedicated to the study of the aerodynamic coefficients of vehicles under the shelter effect of bridge tower.

The aerodynamic coefficients of different vehicles on the same lane (Lane 1) are shown in Figure 13. The travelling bus was selected for the research of shelter effect of the bridge tower on the aerodynamic coefficients of vehicles in different lanes, which is shown in Figure 14. As it can be seen from Figure 13a, the shelter effects of the bridge tower on aerodynamic coefficients of vehicles are different. $C_{y}$ of the vehicle decreases first when it passes through the shelter area of the bridge tower and reaches the minimum value in the shelter area. As the vehicle moves out of the shelter area, $C_{y}$ increases gradually. In the bridge tower range, the directions of $C_{y}$ are even reverse. Because of the difference of the aerodynamic shape of the vehicle, the articulated lorry with larger lateral area has a larger absolute value of $C_{y}$. As shown in Figure $13 \mathrm{~b}, C_{z}$ of the articulated lorry and travelling bus increase slightly in the tower shelter area as well, while $C_{z}$ of the commercial van increases relatively significantly and fluctuates greatly in this area. With regard to $C_{M x}$ of three types of vehicles shown in Figure 13c, the shelter range of bridge tower can effectively increase $C_{M_{x}}$ of the articulated lorry and commercial van, but the effect on the travelling bus is not obvious. The shelter effect of the bridge tower on $C_{M y}$ of the vehicle is shown in Figure 13d, but the effects are relatively limited. The change law of $C_{M z}$ is shown in Figure $13 \mathrm{e}$. According to the results, $C_{M Z}$ of the articulated lorry and travelling bus increases, but the bridge tower has less influence on the commercial van. The shelter effect of bridge towers has a great effect on the aerodynamic coefficients of the vehicles. For different types of vehicles, the aerodynamic shape of vehicles should be considered. In Figure 14, aerodynamic coefficient of the vehicle in Lane 2 is more stable than in Lane 1 . Since Lane 1 is closer to the bridge tower, it is greatly affected by the bridge tower, Lane 2 is farther from the bridge tower, and the shelter effect of the bridge tower is weaker, but it will still have a greater impact. 


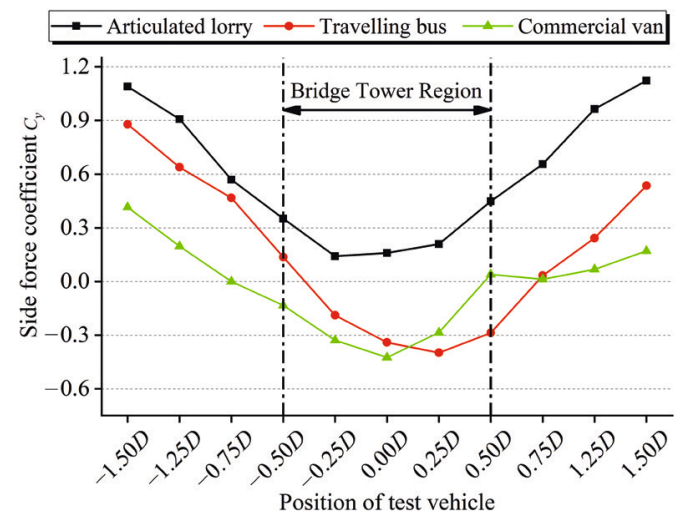

a)

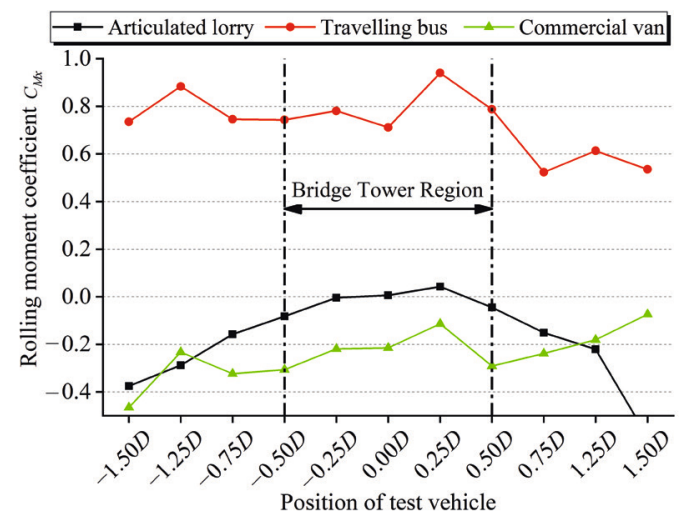

c)

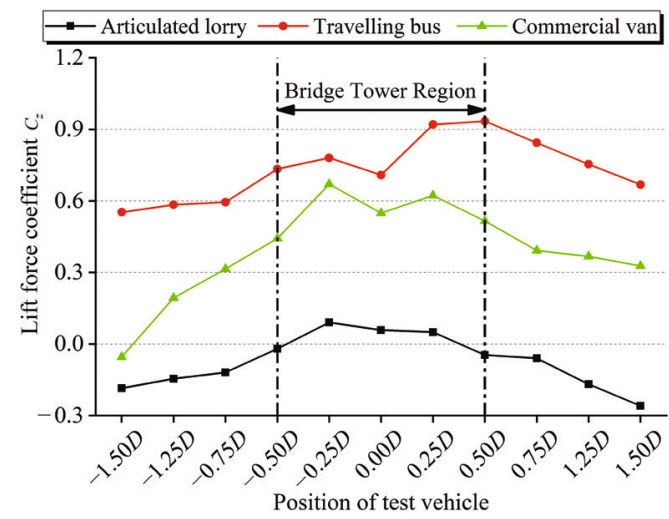

b)

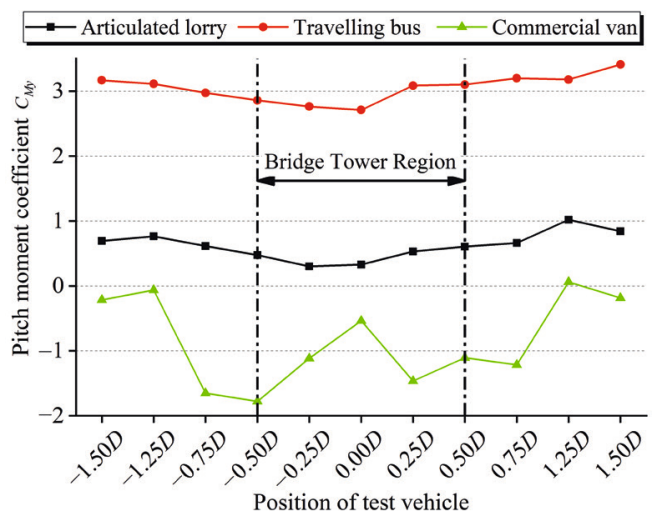

d)

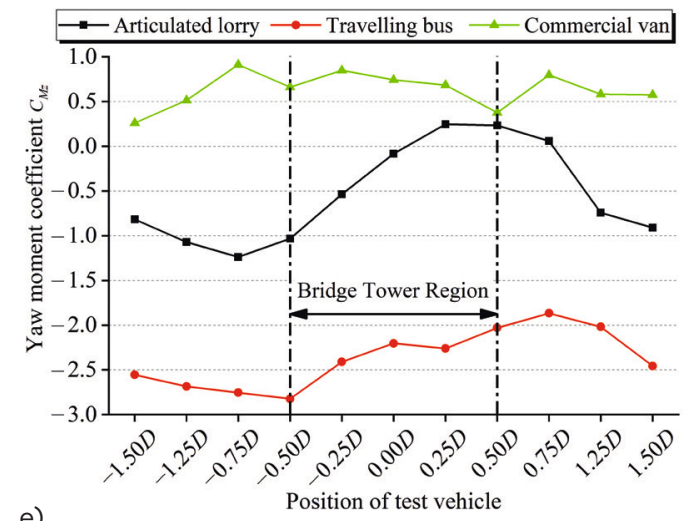

Figure 13. Sheltering effect of the bridge tower on the aerodynamic coefficients of different vehicles 

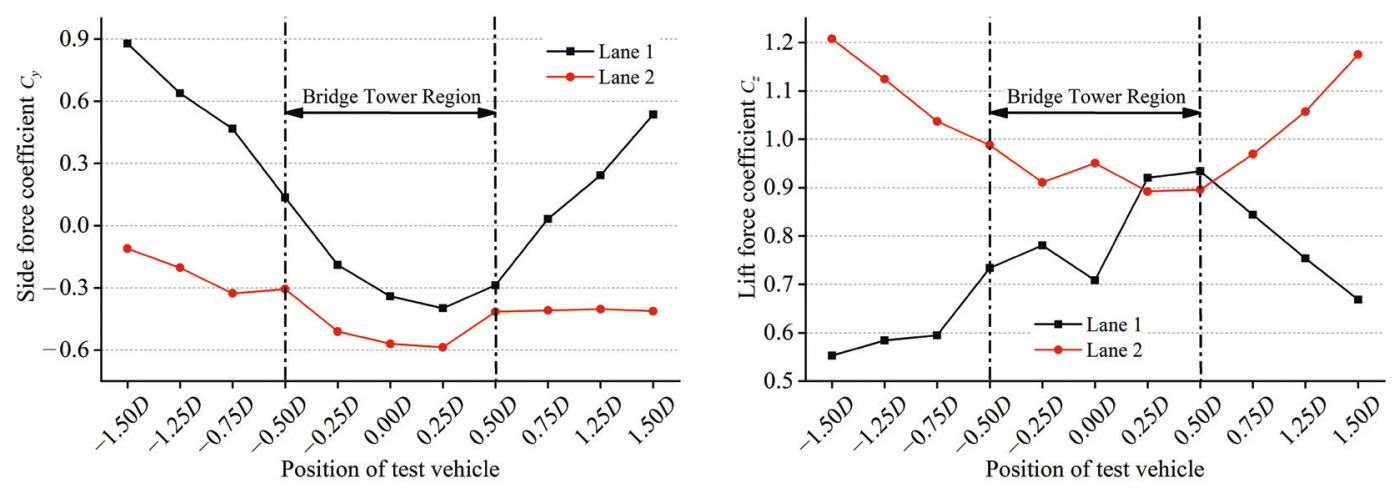

a)

b)
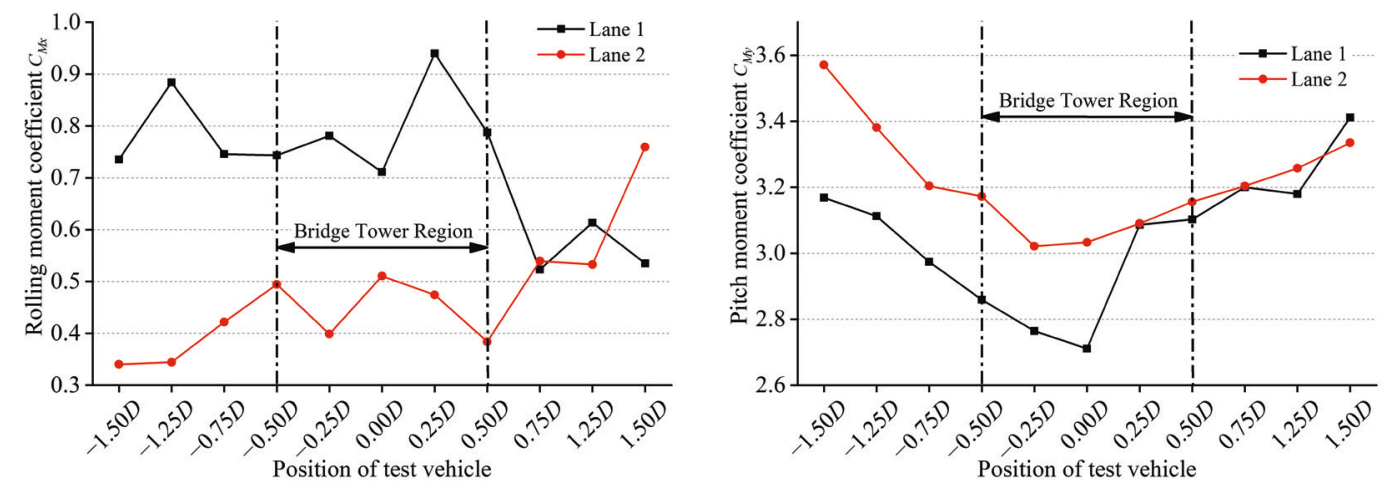

c)

d)

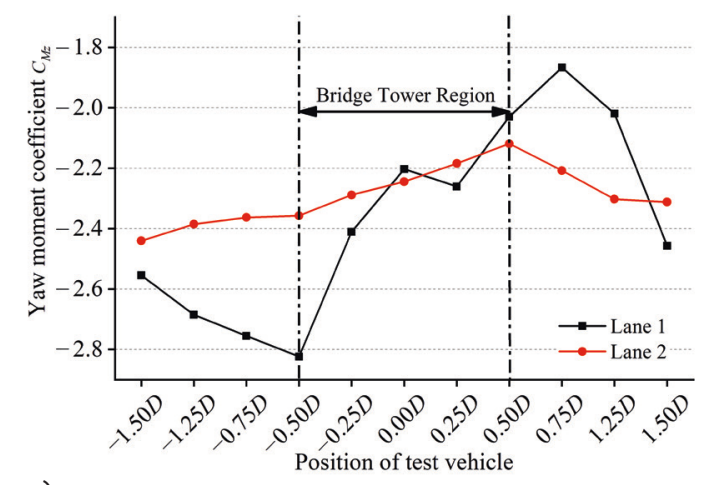

e)

Figure 14. Sheltering effect of the bridge tower on the aerodynamic coefficients of travelling bus in different lanes 


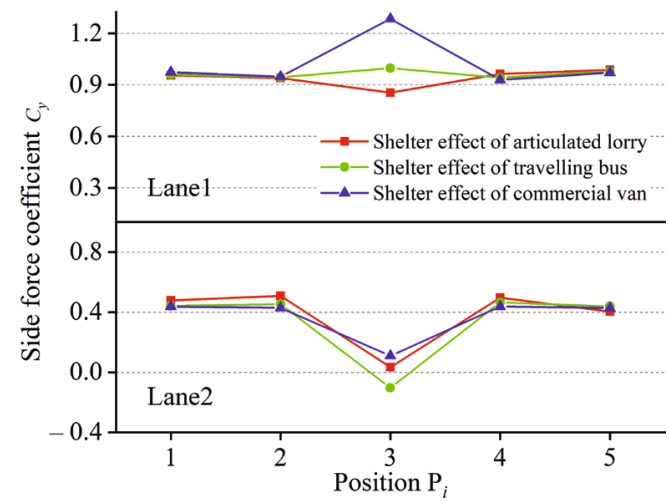

a)

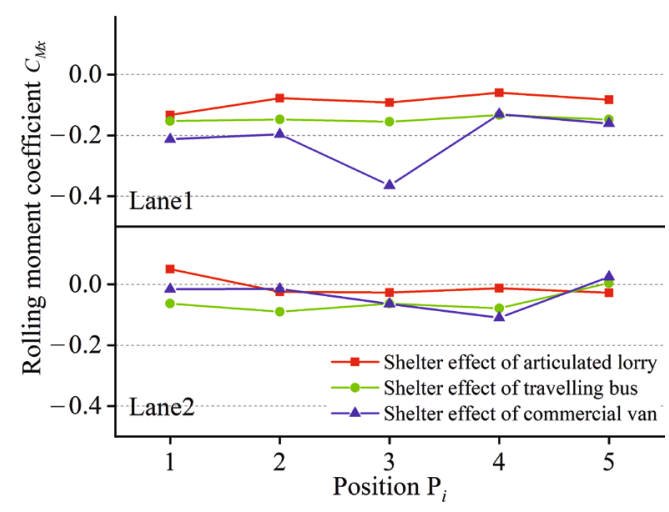

c)

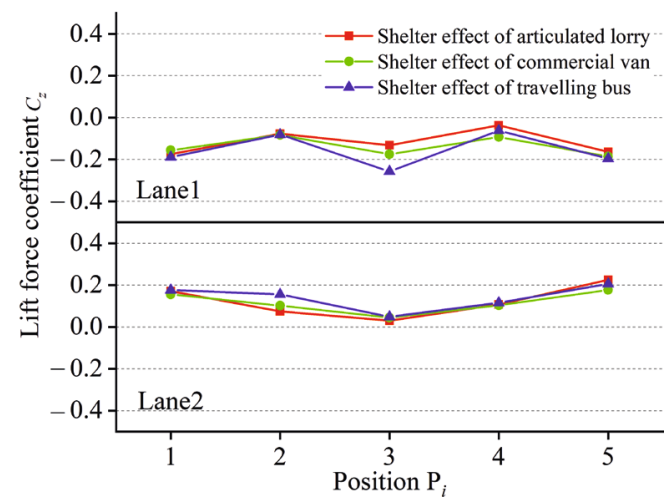

b)

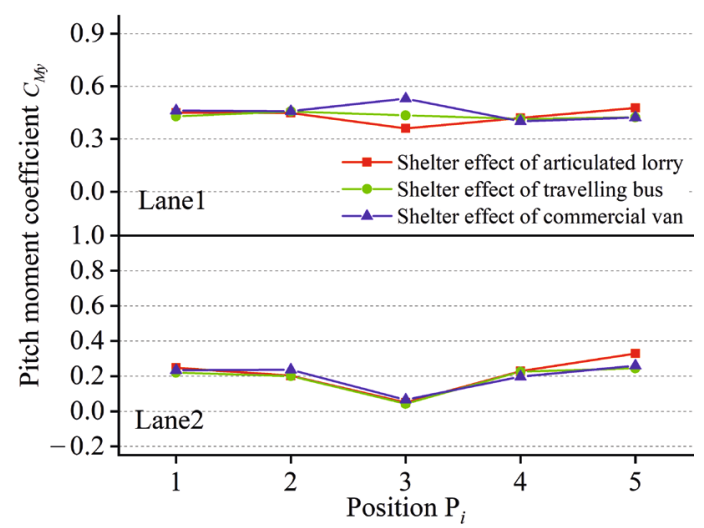

d)

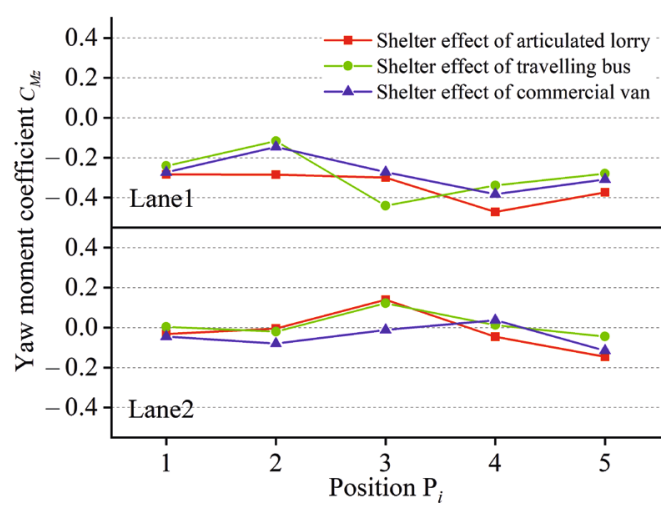

e)

Figure 15. The shelter effect of different types of vehicles on the aerodynamic coefficients of the travelling bus during overtaking 


\subsection{Interference between different vehicles in adjacent lanes}

In the process of vehicle running, there will be vehicle intersection. When vehicles intersect, it will cause the joint action of intersecting vehicles. The interaction of aerodynamic shapes of the vehicles will bring sudden change of vehicle aerodynamic coefficients, which has a great impact on vehicle safety and comfort. In order to study the shielding effect of the vehicles, the aerodynamic coefficients of travelling bus on the truss model under the intersections with articulated lorry, travelling bus and commercial van at the windward side were tested. The test results are shown in Figure 15. In the figures, the red line, green line and blue line represent the effect of the articulated lorry, travelling bus and commercial van on the aerodynamics of the travelling bus, respectively. As shown in Figure 15, each figure is divided into two parts. The upper part indicates that the test vehicle is located in Lane 1 , while the intersection vehicle is located in Lane 2 . The lower part indicates that the test vehicle is located in Lane 2 and the intersection vehicle is located in Lane 1 . Considering the results, it can be seen that the aerodynamic coefficients of vehicles will change abruptly at the junction of vehicle intersection and overlap. The variation of coefficients measured on Lane 1 is much smaller than that measured on Lane 2. Because the vehicle is installed on Lane 1 and the interference vehicle passes through Lane 2, the aerodynamic shape of the interference vehicle will interfere with the aerodynamic shape of the test vehicle less. The vehicle is mounted on Lane 2 and the aerodynamic shape of the test vehicle is obviously disturbed by the interference vehicle. Among the five coefficients, except $C_{M y}$ measured on Lane 1 that is slightly larger than that measured on Lane 2, the other coefficients are smaller than those measured on Lane 2 . The main reason is that Lane 1 is located outside the bridge deck, the wind load acting on the side surface is larger, while Lane 2 is located inside the bridge deck, and the wind is sheltered by the interference vehicle installed on Lane 1 , so the aerodynamic coefficients of vehicles measured are smaller.

\section{Conclusion}

Based on wind tunnel tests of large-scale complex steel truss beams, the aerodynamic coefficients of vehicles under different cases have been tested, and the shelter effects of different wind barriers, bridge tower and interference between vehicles on the aerodynamic coefficients 
of the test vehicles have been measured and analyzed. The following conclusions have been drawn.

1. The wind barriers can provide for effective decrease of wind speed, which generates smaller aerodynamic response of the vehicles. The aerodynamics of vehicles are related to the shape of the vehicles and the parameters of wind barriers, the lower the porosity and the higher the height, the better the effect of the wind barrier is. Generally, the wind barriers can provide sufficient protection performance for the vehicles at the windward side.

2. The sudden change caused by the tower significantly affects the aerodynamic coefficients of all three types of vehicles, especially of the commercial van. Obviously, the influence of the bridge tower on the lateral force is the most direct. In the cases of the same vehicle in different lanes, the lane closer to windward is affected greater than that far away from the windward side.

3. With regard to the sheltering effect of the vehicle in the adjacent lane, the relative side surface area between the test vehicle and the interference vehicle in the adjacent lane influences the aerodynamics of the test vehicle a lot. When the windward areas of the two are close to each other, the impact is the greatest.

\section{Acknowledgements}

This work was supported by the National Key Research and Development Program of China (No. 2018YFC1507800), the National Natural Science Foundation of China (Nos. 51525804, 51708464, 51708465), the Fundamental Research Funds for the Central Universities (No. 2682019CX02) and the Hunan Provincial Transportation Science and Technology Project (No. 201615).

\section{REFERENCES}

Argentini, T., Ozkan, E., Rocchi, D., Rosa, L., \& Zasso, A. (2011). Cross-wind effects on a vehicle crossing the wake of a bridge pylon. Journal of Wind Engineering and Industrial Aerodynamics, 99(6), 734-740. https://doi.org/10.1016/j.jweia.2011.01.021

Avila-Sanchez, S., Pindado, S., Lopez-Garcia, O., \& Sanz-Andres, A. (2014). Wind tunnel analysis of the aerodynamic loads on rolling stock over railway embankments: the effect of shelter windbreaks. Scientific World Journal, 2014, 4-17. https://doi.org/10.1155/2014/421829 
Baker, C. J., \& Reynolds, S. (1992). Wind-induced accidents of road vehicles. Accident Analysis \& Prevention, 24(6), 559-575. https://doi.org/10.1016/0001-4575(92)90009-8

Bocciolone, M., Cheli, F., Corradi, R., Muggiasca, S., \& Tomasini, G. (2008). Crosswind action on rail vehicles: Wind tunnel experimental analyses. Journal of Wind Engineering and Industrial Aerodynamics, 96(5), 584-610. https://doi.org/10.1016/j.jweia.2008.02.030

Charuvisit, S., Kimura, K., \& Fujino, Y. (2004). Effects of wind barrier on a vehicle passing in the wake of a bridge tower in cross wind and its response. Journal of Wind Engineering and Industrial Aerodynamics, 92(7), 609-639. https://doi. org/10.1016/j.jweia.2004.03.006

Cheli, F., Corradi, R., Sabbioni, E., \& Tomasini, G. (2011). Wind tunnel tests on heavy road vehicles: Cross wind induced loads - Part 1. Journal of Wind Engineering and Industrial Aerodynamics, 99(10), 1000-1010. https://doi. org/10.1016/j.jweia.2011.07.009

Cheli, F., Ripamonti, F., Sabbioni, E., \& Tomasini, G. (2011). Wind tunnel tests on heavy road vehicles: Cross wind induced loads-Part 2. Journal of Wind Engineering and Industrial Aerodynamics, 99(10), 1011-1024. https://doi. org/10.1016/j.jweia.2011.07.007

Chen, S. R., \& Cai, C. S. (2004). Accident assessment of vehicles on long-span bridges in windy environments. Journal of Wind Engineering and Industrial Aerodynamics, 92(12), 991-1024.

https://doi.org/10.1016/j.jweia.2004.06.002

Chu, C.-R., Chang, C.-Y., Huang, C.-J., Wu, T.-R., Wang, C.-Y., \& Liu, M.-Y. (2013). Windbreak protection for road vehicles against crosswind. Journal of Wind Engineering and Industrial Aerodynamics, 116, 61-69. https://doi. org/10.1016/j.jweia.2013.02.001

Coleman, S. A., \& Baker, C. J. (1990). High sided road vehicles in cross winds. Journal of Wind Engineering and Industrial Aerodynamics, 36, 1383-1392. https://doi.org/10.1016/0167-6105(90)90134-X

Coleman, S. A., \& Baker, C. J. (1992). The reduction of accident risk for high sided road vehicles in cross winds. Journal of Wind Engineering and Industrial Aerodynamics, 44(1), 2685-2695. https://doi.org/10.1016/0167-6105(92)90060-N

Han, Y., Hu, J., Cai, C. S., Chen, Z., \& Li, C. (2013). Experimental and numerical studies of aerodynamic forces on vehicles and bridges. Wind and Structures, 17(2), 163-184.

https://doi.org/10.12989/was.2013.17.2.163

Han, Y., Li, K., Wang, L., Xu, G. J. (2019). Fatigue Reliability Assessment of Long-span Steel-Truss Suspension Bridges Under the Combined Action of Random Traffic and Wind Loads, Journal of Bridge Engineering, 25(3), 04020003. https://doi.org/10.1061/(asce)be.1943-5592.0001525

He, X. H., Zou, Y. F., Wang, H. F., Han, Y., \& Shi, K. (2014). Aerodynamic characteristics of a trailing rail vehicles on viaduct based on still wind tunnel experiments. Journal of Wind Engineering and Industrial Aerodynamics, 135, 22-33. https://doi.org/10.1016/j.jweia.2014.10.004 
Hucho, W., \& Sovran, G. (1993). Aerodynamics of Road Vehicles. Annual Review of Fluid Mechanics, 25(1), 485-537. https://doi.org/10.1146/annurev.fl.25.010193.002413

Kennedy, J. (1997). Effect of Light Poles on Vehicle Impacts with Roadside Barriers. Transportation Research Record: Journal of the Transportation Research Board, 1599, 32-39. https://doi.org/10.3141/1599-04

Kozmar, H., Procino, L., Borsani, A., \& Bartoli, G. (2012). Sheltering efficiency of wind barriers on bridges. Journal of Wind Engineering and Industrial Aerodynamics, 107-108(Supplement C), 274-284. https://doi.org/10.1016/j.jweia.2012.04.027

Li, Y., Hu, P., Cai, C. S., Zhang, M., \& Qiang, S. (2013). Wind Tunnel Study of a Sudden Change of Train Wind Loads due to the Wind Shielding Effects of Bridge Towers and Passing Trains. Journal of Engineering Mechanics, 139(9), 1249-1259. https://doi.org/10.1061/(ASCE)EM.1943-7889.0000559

Li, Y., Zhang, J., Zhang, M., Wang, Z., \& Guo, J. (2019). Aerodynamic Effects of Viaduct-Cutting Connection Section on High-Speed Railway by Wind Tunnel Tests. Journal of Aerospace Engineering, 32(5), 05019002. https://doi.org/10.1061/(ASCE)AS.1943-5525.0001065

Liu, T., \& Zhang, J. (2013). Effect of landform on aerodynamic performance of high-speed trains in cutting under cross wind. Journal of Central South University, 20(3), 830-836. https://doi.org/10.1007/s11771-013-1554-3

Perera, M. D. A. E. S. (1981). Shelter behind two-dimensional solid and porous fences. Journal of Wind Engineering and Industrial Aerodynamics, 8(1), 93-104. https://doi.org/10.1016/0167-6105(81)90010-6

Schober, M., Weise, M., Orellano, A., Deeg, P., \& Wetzel, W. (2010). Wind tunnel investigation of an ICE 3 endcar on three standard ground scenarios. Journal of Wind Engineering and Industrial Aerodynamics, 98(6), 345-352. https://doi.org/10.1016/j.jweia.2009.12.004

Suzuki, M., Tanemoto, K., \& Maeda, T. (2003). Aerodynamic characteristics of train/vehicles under cross winds. Journal of Wind Engineering and Industrial Aerodynamics, 91(1), 209-218. https://doi.org/10.1016/S0167-6105(02)00346-X

Ti, Z., Zhang, M., Li, Y., \& Wei, K. (2019). Numerical study on the stochastic response of a long-span sea-crossing bridge subjected to extreme nonlinear wave loads. Engineering Structures, 196, 109287. https://doi.org/10.1016/j.engstruct.2019.109287

Wang, H., \& Takle, E. S. (1996). On three-dimensionality of shelterbelt structure and its influences on shelter effects. Boundary-Layer Meteorology, 79(1-2), 83-105. https://doi.org/10.1007/BF00120076

Wu, M., Li, Y., \& Zhang, W. (2017). Impacts of wind shielding effects of bridge tower on railway vehicle running performance. Wind and Structures, 25(1), 63-77. https://doi.org/10.12989/was.2017.25.1.063 
Xu, Y. L., \& Guo, W. H. (2004). Effects of bridge motion and crosswind on ride comfort of road vehicles. Journal of Wind Engineering and Industrial Aerodynamics, 92(7), 641-662. https://doi.org/10.1016/j.jweia.2004.03.009

Xiang, H. Y., Li, Y. L., Chen, B., Liao, H. L. (2014). Protection effect of railway wind barrier on running safety of train under cross winds. Advances in Structural Engineering, 17(8), 1177-1187. https://doi.org/10.1260/1369-4332.17.8.1177

Zhang, J., Wei, K., \& Qin, S. (2019). An efficient numerical model for hydrodynamic added mass of immersed column with arbitrary cross Section. Ocean Engineering, 187, 106192. https://doi.org/10.1016/j.oceaneng.2019.106192

Zhang, J., Zhang, M., Li, Y., \& Fang, C. (2019a). Aerodynamic Effects of Subgrade-Tunnel Transition on High-Speed Railway by Wind Tunnel Tests. Wind and Structures, 28(4), 203-213. https://doi.org/10.12989/was.2019.28.4.203

Zhang, J., Zhang, M., Li, Y., \& Fang, C. (2019b). Comparison of wind characteristics at different heights of deep-cut canyon based on field measurement. Advances in Structural Engineering, 23(2), 219-233. https://doi.org/10.1177/1369433219868074

Zhang, M., Yu, J., Zhang, J., Wu, L., \& Li, Y. (2019). Study on the wind-field characteristics over a bridge site due to the shielding effects of mountains in a deep gorge via numerical simulation. Advances in Structural Engineering, 22(14), 3055-3065. https://doi.org/10.1177/1369433219857859

Zhu, J., \& Zhang, W. (2018). Probabilistic fatigue damage assessment of coastal slender bridges under coupled dynamic loads. Engineering Structures, 166, 274-285. https://doi.org/10.1016/j.engstruct.2018.03.073

Zhu, J., Zhang, W., \& Li, X. (2019). Fatigue damage assessment of orthotropic steel deck using dynamic Bayesian networks. International Journal of Fatigue, 118, 44-53. https://doi.org/10.1016/j.ijfatigue.2018.08.037 